\title{
Sexing Galápagos penguins Spheniscus mendiculus by morphological measurements
}

\author{
Caroline D. Cappello*, P. Dee Boersma \\ Department of Biology, University of Washington, Seattle, WA 98195, USA
}

\begin{abstract}
The ability to identify the sex of individuals is essential in studies of ecology, behavior, and conservation, but reliable methods for sexing species that exhibit low sexual dimorphism are often time consuming or invasive. Previous studies have evaluated the usefulness of morphological measurements as easy and minimally invasive means of sexing seabirds in the field. We used a discriminant function analysis (DFA) to determine the accuracy of sexing Galápagos penguins Spheniscus mendiculus using 6 morphological measurements: bill depth, bill length, head length, gape, flipper length, and foot length. Using these variables, we sexed $95 \%$ of study penguins correctly. Simplified functions, including bill depth and length, or bill depth only, also correctly classified the sex of $95 \%$ of study penguins. We also looked for sexual dimorphism in plumage, estimating the size of the white feather patch underneath the chin. Ninety-five percent of penguins with little to no white chin patch were female, while penguins with larger chin spots were both male and female. We show that Galápagos penguins, a rare and Endangered seabird, may be sexed accurately, even when data are limited to 1 morphological measurement.
\end{abstract}

KEY WORDS: Sex determination - Sexual dimorphism - Morphology · Galápagos penguin · Spheniscus mendiculus $\cdot$ Discriminant function

\section{INTRODUCTION}

Accurate and minimally invasive methods to determine the sex of individuals are important to studies of threatened populations (Clutton-Brock 1985, Zavalaga \& Paredes 1997, Dechaume-Moncharmont et al. 2011). Knowledge of sex is critical to studies of breeding, behavior, ecology, population trends, and management. Sexing individuals of species that display low sexual dimorphism is difficult, however, and often necessitates invasive, time-consuming, and costly procedures, thus hindering studies important for conservation.

Many species of seabirds have low plumage and size dimorphism between sexes, making sexing individuals in the field difficult. Although molecular sex-

\footnotetext{
*Corresponding author: ccappell@uw.edu
}

ing techniques are reliable, they are costly and require permits for blood collection that are often challenging to obtain, especially when working with a rare or endangered species. Sexing birds by morphological measurements is a widespread field technique that is inexpensive, easy to implement, minimally invasive, and can be effective even for species with low sexual dimorphism (Dechaume-Moncharmont et al. 2011). For example, morphological measurements allow for sex classification in several penguin species, including Magellanic Spheniscus magellanicus (references in Vanstreels et al. 2011), Humboldt S. humboldti (Zavalaga \& Paredes 1997, Wallace et al. 2008), African $S$. demersus (Pichegru et al. 2013), gentoo Pygoscelis papua and chinstrap P. antarcticus (Lee et al. 2015), rockhopper Eudyptes

() The authors 2018. Open Access under Creative Commons by Attribution Licence. Use, distribution and reproduction are unrestricted. Authors and original publication must be credited. 
chrysocome (Poisbleau et al. 2010), royal E. schlegeli (Hull 1996), and little penguins Eudyptula minor (Arnould et al. 2004).

The Galápagos penguin S. mendiculus is the rarest penguin species and is listed as Endangered on the IUCN Red List of Threatened Species (Boersma et al. 2013). The population has 1500 to 4700 individuals and faces mounting threats such as the increasing frequency and intensity of El Niño, introduced predators such as rats and cats, fisheries, and habitat degradation (Boersma et al. 2013). Threats that limit food availability, such as El Niño and overfishing, may affect males and females differently if they forage at separate locations or depths or take different prey, as is the case in other penguins (Walker \& Boersma 2003, Pichegru et al. 2013). Studies of Galápagos penguins will be more informative if the sex of individuals can be easily determined. Male and female Galápagos penguins look similar, but males are larger and have more distinct markings (Boersma 1977). These distinctions in size and plumage are subtle, however, and difficult to detect even when the birds are in hand. To assess morphology-based sex predictors, we collected morphological data for individuals whose sex was determined with genetic analysis. We then used a linear discriminant analysis to test the predictive ability of morphological measurements in sexing Galápagos penguins.

\section{MATERIALS AND METHODS}

\section{Data collection}

\section{Known-sex samples}

We determined the sex of 61 (25 female, 36 male) adult Galápagos penguins through genetic analysis. We took blood samples from penguins of unknown age and breeding status captured on Fernandina, Isabela, Santiago, and Bartolomé Islands in Galápagos, Ecuador $\left(0.95^{\circ} \mathrm{S}, 90.97^{\circ} \mathrm{W}\right)$ in 2010 and 2011 . We collected blood through venipuncture of the interdigitary vein in the foot webbing and stored it in lysis buffer. Dr. Patricia Parker sexed individuals at the University of Missouri-St. Louis using a PCR-based approach (as decribed in Fridolfsson \& Ellegren 1999).

\section{Predictor variables}

During 8 research trips between 2010 and 2014, we used dial calipers $( \pm 0.1 \mathrm{~mm})$ to measure bill length (length of exposed culmen), bill depth (measured at the nares), head length (occiput to tip of bill), and gape of the 61 penguins that we sexed genetically. We also measured flipper length (middle of elbow joint to tip) and foot length (back of heel to tip of middle toe) with a zero-stop ruler $( \pm 1 \mathrm{~mm}$ ) (after Boersma 1974). We used the median measurement for each bird that we measured more than once as an adult, and the same person (P.D.B.) took all of the measurements. Because Galápagos penguins are difficult to capture, and non-invasive sexing techniques are preferable, we estimated the width of the patch of white feathers that grows under the chin (referred to as the chin spot). This can be estimated from several feet away and without capturing the individual. We assigned each individual to 1 of 4 categories: 0 (no chin spot), 1 (<0.5 cm across), $2(0.5-1.5 \mathrm{~cm})$, and 3 $(>1.5 \mathrm{~cm})$. For 41 individuals (16 females, 25 males), we also noted if the white chin was mottled with dark feathers.

\section{Statistical procedures}

We calculated mean and standard deviation for all continuous variables for each sex of our 61 knownsex penguins. To assess the overall size difference between sexes, we performed a 1-way analysis of variance for each variable using the $\mathrm{lm}$ function from the stats package in $\mathrm{R}$. We then used morphological measurements from our known-sex samples to determine discriminant functions. We performed the discriminant analysis using the lda function from the MASS package in R (Venables \& Ripley 2002). To assess the strength of the relationship between each variable and the canonical axis, we standardized the raw canonical coefficients to produce Pearson product-moment bivariate correlations (i.e. structure coefficients). To test the predictive ability of our models, we used a jackknife (leave-one-out) approach that predicted the sex of each individual based on the model fit when leaving that individual out of the dataset. We repeated this for each individual, and calculated the proportion of individuals correctly sexed.

To determine our precision in measuring each morphological trait, we calculated the coefficient of variation for each trait of every adult Galápagos penguin that was measured 3 or more times between 1970 and 2017 ( $\mathrm{n}=7-21$, depending on trait). We averaged these values to obtain 1 coefficient of variation per morphological variable. Because plumage may be more variable over time than bony structures, we fit a linear mixed effects model using all birds 
Table 1. Mean, standard deviation, range, and results of 1-way ANOVA for morphological measurements for known-sex male $(\mathrm{n}=36)$ and female $(\mathrm{n}=25)$ Galápagos penguins. Mean coefficient of variation $(\mathrm{CV})$ and sample size (n) from repeated measurements of individuals are given for each trait. Significance is indicated by asterisks $\left({ }^{* * *} p<0.001\right)$

\begin{tabular}{|c|c|c|c|c|c|c|}
\hline \multirow[t]{2}{*}{ Variable (mm) } & \multicolumn{2}{|c|}{ Females } & \multicolumn{2}{|c|}{ Males } & \multirow[t]{2}{*}{$F_{1,59}$} & \multirow[t]{2}{*}{$\mathrm{CV}(\mathrm{n})$} \\
\hline & Mean \pm SD & Range & Mean \pm SD & Range & & \\
\hline Bill depth & $16.0 \pm 0.7$ & $14.8-17.6$ & $18.7 \pm 0.8$ & $16.2-20.0$ & $163.6^{* * *}$ & $2.22(21)$ \\
\hline Head length & $115.8 \pm 3.5$ & $111.3-124.3$ & $123.4 \pm 3.1$ & $117.1-128.4$ & $82.7^{* * *}$ & $2.04(7)$ \\
\hline Bill length & $54.3 \pm 1.6$ & $51.9-58.3$ & $58.9 \pm 2.3$ & $51.4-62.1$ & $73.1^{* * *}$ & $1.77(21)$ \\
\hline Flipper & $120.3 \pm 4.6$ & $112.0-128.0$ & $129.0 \pm 3.9$ & $120.0-140.0$ & $62.3^{* * *}$ & $2.85(17)$ \\
\hline Foot & $89.6 \pm 4.3$ & $75.0-96.0$ & $97.0 \pm 3.1$ & $87.0-101.0$ & $60.9^{* * *}$ & $2.31(17)$ \\
\hline Gape & $20.4 \pm 2.2$ & $16.4-26.0$ & $23.9 \pm 2.1$ & $20.7-29.4$ & $39.0^{* * *}$ & $8.70(16)$ \\
\hline
\end{tabular}

from our database with multiple chin spot measures ( $\mathrm{n}=68)$. We included chin spot as the response variable, time since first check and amount of breedingassociated feather loss around the bill as fixed effects, and allowed random intercepts by individual ID.

\section{RESULTS}

Males were significantly larger than females in all morphological variables in Galápagos penguins (Table 1). Using all continuous variables (we excluded chin spot from the discriminant analysis because data were categorical), we determined the following function:

$$
\begin{gathered}
\left.D_{1}=0.042 \text { (Bill length) }+0.895 \text { (Bill depth }\right) \\
+0.095 \text { (Flipper })+0.019(\text { Foot }) \\
+0.038(\text { Head })+0.082 \text { (Gape) }-38.224
\end{gathered}
$$

This function correctly classified the sex of $96.7 \%$ of study birds $(97.2 \%$ of males, $96 \%$ of females; Wilk's lambda $=0.191, \mathrm{p}<0.001)$. One male and $1 \mathrm{fe}-$ male were misclassified. The distribution of discriminant scores is illustrated in Fig. 1a, and the canonical loadings for each variable are given in Table 2. Using the jackknife procedure, we correctly predicted the

Table 2. Pearson product-moment bivariate correlations between each morphometric variable measured in Galápagos penguins and the canonical function. Bill depth, head length, and bill length had the largest loadings and best described the variance between males and females

\begin{tabular}{|lc|}
\hline Variable & Structure correlations \\
\hline Bill depth & 0.95 \\
Head length & 0.85 \\
Bill length & 0.83 \\
Flipper & 0.80 \\
Foot & 0.79 \\
Gape & 0.70 \\
\hline
\end{tabular}
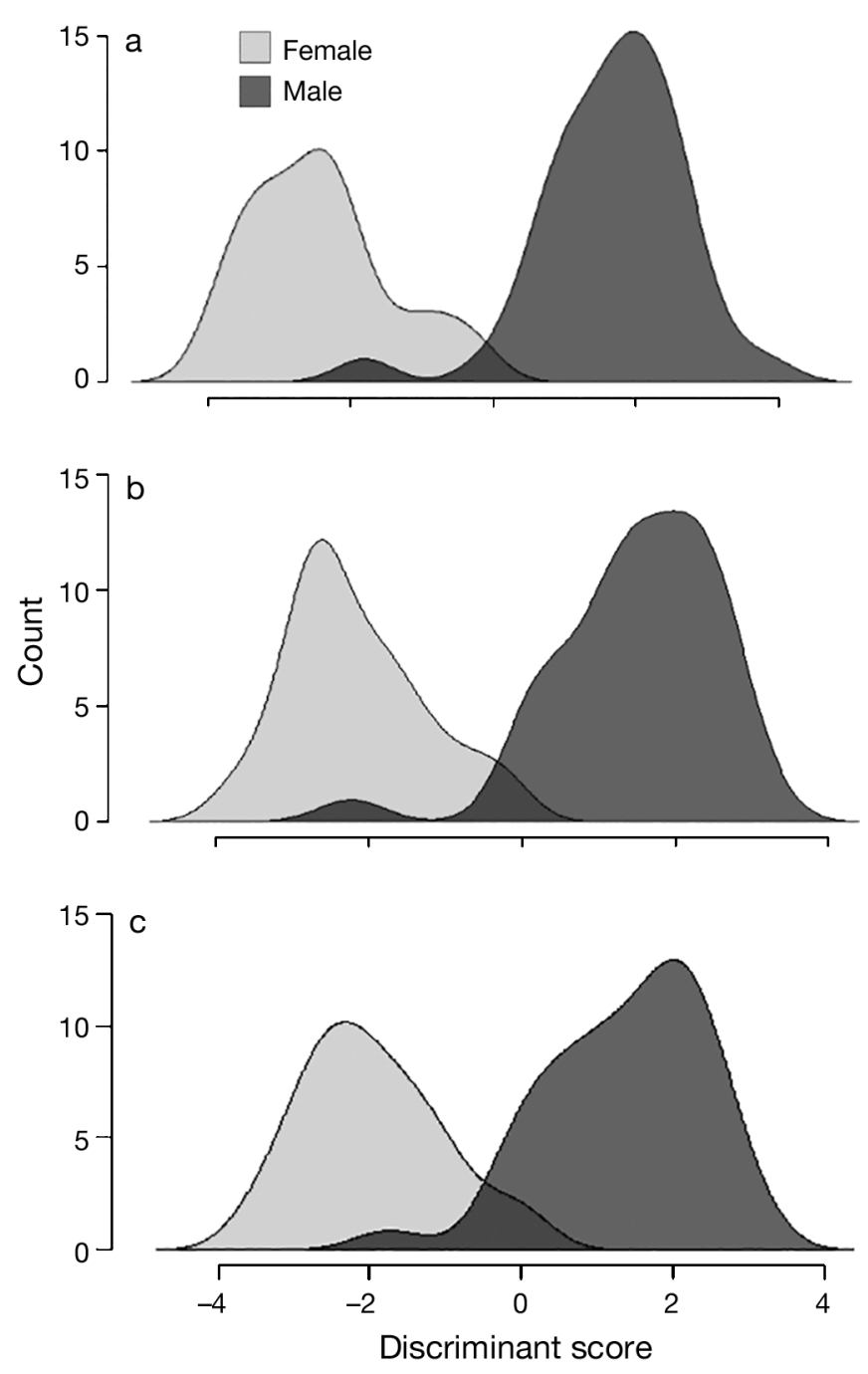

Fig. 1. Distribution of discriminant scores for Galápagos penguins using (a) bill depth, bill length, head length, gape, flipper length, and foot length $\left(D_{1}\right)$, (b) bill depth and bill length $\left(D_{2}\right)$, and (c) bill depth only $\left(D_{3}\right)$. The overlap between curves represents individuals misclassified by the functions before cross-validation. In (a), 1 male and 1 female were misclassified. In (b) and (c), 1 male and 2 females were misclassified 
sex of $95.1 \%$ of study birds, misclassifying 1 male and 2 females.

Because a discriminant function using only 1 or 2 variables may necessitate less handling time and reduce the stress on each individual, we derived 2 additional functions, one restricting the variables to bill length and bill depth, and one using bill depth only. We selected these variables because they best explained the variance in the previous function (Table 2). We selected bill length instead of head length because bill length is included within head length and was measured with higher precision than head length (Table 1). Using bill depth and length, we derived the following function:

$$
\begin{gathered}
D_{2}=0.210 \text { (Bill length) }+1.021 \text { (Bill depth) } \\
-29.950
\end{gathered}
$$

This second function also classified $96.7 \%$ of study birds correctly, although it had a higher Wilk's lambda than the first function (Wilk's lambda $=0.229$, $\mathrm{p}<0.001$; Fig. 1b). Our jackknifed accuracy was $95.1 \%$.

Reducing the equation to include bill depth only, we produced the following function:

$$
D_{3}=1.254 \text { (Bill depth) }-22.06
$$

$D_{3}$ correctly classified $95.1 \%$ of birds before and after jackknifing ( $<<0.001$; Fig. 1c). Using this third function, we calculated the discriminating threshold between male and female bill depth. We set $D_{3}$ to -0.49 (the intersection between male and female discriminant scores) and solved for bill depth, finding $17.2 \mathrm{~mm}$ to be the threshold between male and female bill depth, above which a penguin would be classified as male, and below which a penguin would be classified as female.

Bill length had the lowest coefficient of variation, followed by head length, bill depth, foot, flipper, and gape (Table 1). We found substantial overlap between male and female chin spot size. Fortythree percent of penguins with a chin spot of category 2 were female, while $57 \%$ were male. Thirtyseven percent of penguins with a chin spot of category 3 were female, and $63 \%$ were male. There was less overlap in the little-to-no chin spot categories ( 0 and 1$)$, with $95 \%$ of the group being female. We found that chin spot size did not differ over time (estimate -0.00003 , profile confidence interval -0.002 to 0.001 ) but decreased with feather loss associated with breeding $(-0.01 ;-0.16$ to -0.04$)$. Mottling in the chin spot did not provide additional clarity (44\% of females and $60 \%$ of males had mottled chins).

\section{DISCUSSION}

Knowing the sex of animals is critical for many studies of their ecology and behavior. For a rare and Endangered species like the Galápagos penguin, finding effective means of sexing individuals while reducing stress is of value. We show that Galápagos penguins are sufficiently sexually dimorphic that they can be sexed accurately with just a few morphological measurements.

Bill depth, bill length, and head length (which includes bill length as part of the measurement) were the strongest morphological indicators of sex. Bill measurements were the best predictors of sex for all other Spheniscus penguins (Wallace et al. 2008, Vanstreels et al. 2011, Pichegru et al. 2013), several other penguin species (Hull 1996, Lee et al. 2015), and seabird families (Grecian et al. 2003, Ferrer et al. 2016, Bourgeois et al. 2017). In reducing our discriminant function to bill depth only, we correctly sexed $>95 \%$ of study penguins. This accuracy is comparable to the values reported in similar studies (91\% in Arnould et al. 2004 and Lee et al. 2015; 93 and $97 \%$ in Hull 1996; 96 \% in Poisbleau et al. 2010). Chin spot size was potentially useful in identifying individuals with no or small chin spots as female, but was otherwise unreliable at separating the sexes and became smaller as breeding birds shed feathers around their bill. The ability to sex these penguins using only one measurement means less time in hand and less stress for each individual bird.

Bony structures like the bill were easier to measure precisely than the flipper, foot, or chin, which can vary depending on state of plumage or wear of toenail. Structures that lie under loose skin, like the occiput (bony point at the back of the skull used to measure head length), are more difficult to find than the exposed structures of the bill and may lead to more variation in measurement.

Sexual size dimorphism in Spheniscus penguins is likely a result of breeding behavior and niche segregation (Ainley \& Emison 1972, Boersma 1977, Walker \& Boersma 2003). Male Spheniscus penguins vie for nests and mates through physical competitions, and larger males have an advantage (Renison et al. 2002). Females fight less frequently and with less intensity (Renison et al. 2003). Resource partitioning between sexes in sexually dimorphic species has been suggested for a number of bird species (Selander 1966, Ainley \& Emison 1972, Boersma 1977, Walker \& Boersma 2003). Though male and female Galápagos penguins forage in the same horizontal range (Steinfurth et al. 2008), the sexual dimorphism in bill size 
could result in males eating larger prey than females. Males may also dive deeper than females, as in African penguins (Pichegru et al. 2013).

By establishing techniques for sexing individuals that are quick, minimally invasive, and accurate, we can better understand threats to endangered populations. Morphometric measurements, particularly those of bill depth and length, are accurate indicators of Galápagos penguin sex and are relatively easy to measure, making them useful tools for researchers.

Acknowledgements. This research was done in collaboration with Galápagos National Park (permit nos. PC-47-10 through PC-61-16) and received funding from the David and Lucile Packard Foundation, Galápagos Conservancy, Disney Conservation Fund, National Geographic, Leiden Conservation Foundation, Detroit Zoological Society, Sacramento Zoo, and the Wadsworth Endowed Chair in Conservation Science. We thank G. Merlen, N. d'Ozouville, B. Henemen, P. Sayo, and G. Quezada for support in the field. We are grateful to P. Parker and her lab for genetic sexing. J. Cerchiara, E. Fricke, N. Gownaris, C. Gravelle, K. Holt, G. Orians, G. Rebstock, J. Smith, O. Woods, and 4 reviewers provided helpful feedback with analysis and writing.

\section{LITERATURE CITED}

Ainley DG, Emison WB (1972) Sexual size dimorphism in Adelie penguins. Ibis 114:267-271

Arnould JPY, Dann P, Cullen JM (2004) Determining the sex of little penguins (Eudyptula minor) in northern Bass Strait using morphometric measurements. Emu 104: 261-265

Boersma PD (1974) The Galápagos penguin: a study of adaptations for life in an unpredictable environment. $\mathrm{PhD}$ dissertation, Ohio State University, Columbus, $\mathrm{OH}$

Boersma PD (1977) An ecological and behavioral study of the Galápagos penguin. Living Bird 15:43-93

Boersma PD, Steinfurth A, Merlen G, Jiménez-Uzcátegui G, Vargas FH, Parker PG (2013) Galápagos penguin (Spheniscus mendiculus). In: García-Borboroglu P (ed) Penguins: natural history and conservation. University of Washington Press, Seattle, WA, p 264-302

Bourgeois K, Bromzée S, Welch JR, Russell JC (2017) Sex and geographic variation in grey-faced petrel (Pterodroma gouldi) morphometrics. Waterbirds 40:144-153

Clutton-Brock T (1985) Sex ratio variation in birds. Ibis 128: 317-329

* Dechaume-Moncharmont FX, Monceau K, Cézilly F (2011) Sexing birds using discriminant function analysis: a critical appraisal. Auk 128:78-86

Editorial responsibility: Rory Wilson,

Swansea, UK
Ferrer M, Morandini V, Perry L, Bechard M (2016) Sex determination by morphological measurements of blackbrowed albatross (Thalassarche melanophrys) using discriminant analysis. Waterbirds 39:295-299

Fridolfsson AK, Ellegren H (1999) A simple and universal method for molecular sexing of non-ratite birds. J Avian Biol 30:116-121

Grecian VD, Diamon AW, Chardine JW (2003) Sexing razorbills Alca torda breeding at Machias Seal Island, New Brunswick, Canada, using discriminant function analysis. Atl Seabirds 5:73-80

Hull CL (1996) Morphometric indices for sexing adult royal Eudyptes schlegeli and rockhopper E. chrysocome penguins at Macquarie Island. Mar Ornithol 24:23-27

Lee WY, Jung JW, Han YD, Chung H, Kim JH (2015) A new sex determination method using morphological traits in adult chinstrap and gentoo penguins on King George Island, Antarctica. Anim Cells Syst 19:156-159

* Pichegru L, Cook T, Handley J, Voogt N, Watermeyer J, Nupen L, McQuaid CD (2013) Sex-specific foraging behaviour and a field sexing technique for Endangered African penguins. Endang Species Res 19:255-264

* Poisbleau M, Demongin L, van Noordwijk HJ, Strange IJ, Quillfeldt P (2010) Sexual dimorphism and use of morphological measurements to sex adults, immatures and chicks of rockhopper penguins. Ardea 98:217-224

* Renison D, Boersma PD, Martella MB (2002) Winning and losing: causes for variability in outcome of fights in male Magellanic penguins (Spheniscus magellanicus). Behav Ecol 13:462-466

Renison D, Boersma PD, Martella MB (2003) Fighting in female Magellanic penguins: when, why, and who wins? Wilson Bull 115:58-63

Selander RK (1966) Sexual dimorphism and niche utilization in birds. Condor 68:113-151

* Steinfurth A, Vargas FH, Wilson RP, Spindler M, Macdonald DW (2008) Space use by foraging Galápagos penguins during chick rearing. Endang Species Res 4:105-112

Vanstreels RET, Adornes AC, Ruoppolo V, Canabarro PL, Silva-Filho RP, Catão-Dias JL (2011) Gender determination from morphometrics in migrating Magellanic penguins Spheniscus magellanicus. Mar Ornithol 39: 215-220

Venables WN, Ripley BD (2002) Modern applied statistics with S, 4th edn. Springer, New York, NY

Walker BG, Boersma PD (2003) Diving behavior of Magellanic penguins (Spheniscus magellanicus) at Punta Tombo, Argentina. Can J Zool 81:1471-1483

Wallace RS, Dubach J, Michaels MG, Keuler S, Diebold ED, Grzybowski K, Teare JA (2008) Morphometric determination of gender in adult Humboldt penguins (Spheniscus humboldti). Waterbirds 31:448-453

Zavalaga CB, Paredes R (1997) Sex determination of adult Humboldt penguins using morphometric characters. J Field Ornithol 68:102-112

Submitted: June 25, 2017; Accepted: December 8, 2017 Proofs received from author(s): March 15, 2018 